\title{
A Preliminary Overview of Trends of Oromo Studies in and Outside Ethiopia ${ }^{1}$
}

\author{
Alemu Alene Kebede ${ }^{2}$ \\ Yirsaw Tadele Alem ${ }^{3}$ \\ *Corresponding Author: Alemu Alene Kebede, Assistant Professor of Ethiopian Studies in Debre \\ Markos University (Ethiopia), College of Social Science \& Humanities, Department of History \& Heritage \\ Management
}

\begin{abstract}
This paper is a preliminary overview of trends of Oromo Studies. The Oromo belonged to the Cushitic group of peoples who have been living in East Africa for thousands of years. Since the Oromo are one of the largest ethnic groups in Ethiopia attention was given by foreign and Ethiopian scholars for the study of the social, cultural, economic and political aspect of the Oromo people. In due course, Oromo Studies was initiated in Europe in the late 1830s and early 1840s by foreign scholars. At home, since 1960s, Oromo Studies was also given some attention in Ethiopian Studies. As a result, Oromo Studies contributed a lot in developing knowledge on Oromo culture and history. This paper considered Oromo Studies by dividing into three phases. The first phase is from its beginning in the late 1830s up to 1950s. The second phase is from 1960s up to the early 1980s. The third phase is from the end of 1980s to the present time. Lastly it considered major areas of disagreement among Oromo and non-Oromo as well as foreign scholars on the Oromo history and culture.
\end{abstract}

Keywords: Ethiopia, Ethiopian Studies, Oromo, Oromo Studies

\section{INTRODUCTION}

Ethiopia is the home of about eighty different ethnicities. The Oromo are the largest single ethnic group in Ethiopia, constituting roughly one third of the population. They have managed excellently well to create a common feeling of belongingness during the last three or four decades. With regard to their population number, figures vary with authors and some Oromo claim to be as many as 50 per cent of the population of the country. The majority of their population lives in rural areas (Pausewang, 2009:1-2). The Oromo are also one of the very largest ethnic groups in East Africa (Asmarom, 2000: xiv).

The Oromo belonged to the Cushitic group of peoples who have been living in East Africa for thousands of years. They are one of the indigenous peoples of what is today Ethiopia and the Horn of Africa (Asmarom, 2000: xiv). Over the last four centuries, centrifugal forces within their ethnic body have overshadowed centripetal ones. As a result, their northern and southern antipodes even lost the knowledge of each other's existence. The language, however, remained amazingly homogeneous. In the course of their expansion between the sixteenth and eighteenth centuries and later, they assimilated many alien groups, an event which enabled the Oromo to continuously enlarge their ethnic body. The success of their great migration and conquest is largely associated with the expansionist ideology inherent in their Gada system (Hultin, 1975: 273-84).

Through this process of assimilation, by intensive contact with heterogeneous groups and also as a result of their penetration into different environments, which demanded various forms of adaptation, the Oromo have developed cultural diversity. On Ethiopian territory we can distinguish five major clusters such as the Southeastern Oromo (Barentu and Arsi) who are culturally to some extent linked

\footnotetext{
${ }^{1}$ This work is original and not submitted/ published elsewhere with other publishers.

${ }^{2}$ Assistant Professor of Ethiopian Studies in Debre Markos University (Ethiopia), College of Social Science \& Humanities, Department of History \& Heritage Management, Email: alemualene @ gmail.com; ORCID ID: http://orcid.org/0000-0001-8321-7763

${ }^{3}$ Co-Researcher, Debre Markos University (Ethiopia), College of Social Science \& Humanities, Department of History \& Heritage Management, Email:yirsaw2000@gmail.com
} 
with the Somali and their Islam religion; the Southern Oromo (Borana and Guji) who have to a large extent retained their traditional patterns of culture and still uphold their age-grade system (gada); the Shawa-Oromo (Tulama) in the center, who were converted to Orthodox Christianity in the nineteenth century and whose culture has become very close to that of the neighboring Amhara; the Western Oromo (Macha), who were partly Islamized and converted by European Christian missions; and the Northern Oromo, along the highland escarpment of Wollo and Tigre, who developed a particular type of Muslim culture. Because of the widening cultural divergence between different groups, the ethnic cohesion of the Oromo gradually diminished (Braukamper, 1982-83: 2-3).

The Oromo language Afaanoromo is one of the widely spoken languages of Eastern Africa. Traditionally, the Oromo religion is centered on Waaqa, God. Ayanas are like saints and the Qallu are the priests. Many Oromo also follow Islam and Christianity. The Oromo are well known by their ancient institution, the Gada system. It is a highly developed democratic system, based on election of leaders every eight years. Elected Gada officials held public offices only for a single eight years period (Muhammed, 1983: 6-7; Asefa, 1983:26; Ezekiel, 2018: 4-11).

Since the Oromo are one of the largest ethnic groups in Ethiopia, in the $20^{\text {th }}$ century, some attention was given by foreign and Ethiopian scholars for the study of the social, cultural, economic and political aspect of the Oromo people. In due course, Oromo Studies was initiated in Europe in the late 1830s and early 1840s by foreign scholars (Pankhurst, 1976: 205). At home, since 1960s, Oromo Studies was also given some attention in the Institute of Ethiopian Studies and issues dealing with Oromo history and culture were considered on limited scale by Ethiopian scholars, most of whom are the Oromo (Asefa, 1966: 117-123). However, Oromo scholars strongly complain that Institute of Ethiopian Studies, at home, did not allow them to come with their own perspective and interpretation about the Oromo culture and history ((Muhammed Hassen (1990: Xi), Asefa (1996: 106), Asmerom (2000: xiv)), a condition which was said to have forced some Oromo scholars to leave their country and take asylum in foreign countries, especially in North America and Europe.

Gradually the Ethiopian Oromo living abroad reached the level of establishing their own studies association known as Oromo Studies Association which was established in 1986 (Ezekiel, 2017). Since this association was established by Oromo expatriate scholars, most of whom are working in the universities of developed countries, its members engaged themselves largely in the study of the sociocultural, economic and political conditions of the Oromo and published their research findings in their journal called Journal of Oromo Studies (OSA, 2010), which has been published continuously since 1993 (OSA, 2018).

Due to the production of large number of literature on various aspects of the Oromo people by the members of Oromo Studies Association, these days there is great tension especially among Oromo \& non-Oromo Ethiopian scholars on the historical and cultural aspects of the Oromo people. They have also contradictory narrations on various aspects of the Oromo people. This contributed to the existence of lack of political consensus, which in turn led to the existance of political instability in the country.

Therefore, this paper focuses on trends of Oromo Studies in and out of the country and major areas of disagreement among scholars on various historical and cultural aspects of the Oromo. In order to achieve the main objective of the paper the following questions were given due attention Who are the Oromo? What is their status in the settlement history of the Ethiopian region in particular and the Horn of Africa in general? When? Where? By whom Oromo Studies was initiated? What were the efforts made abroad and at home to develop Oromo Studies? What are the challenges that Oromo Studies faced, especially at home? What are the measures taken by Oromo scholars to cope with these challenges? What are major areas of disagreements among Ethiopian and non-Ethiopian scholars on Oromo Studies? This paper has several significances. Firstly, it provides relatively comprehensive information on the genesis and development of Oromo Studies from the late 1830s to the present, which could be helpful in enriching our knowledge of Ethiopian history. Secondly, it indentifies major areas of disagreement among scholars on Oromo history and culture, which help scholars to undertake further investigation to solve those disagreements based on various innovative sources of information. Thirdly, this paper tried to show the way out for disagreements that exist among Ethiopian scholars on various aspects of Oromo Studies. 


\section{MethodS AND MATERIALS}

This paper is aimed at analyzing trends of Oromo Studies in and out of the country and major areas of disagreement among scholars on the historical, cultural and economic aspects of the Oromo. Hence, it is fact convening paper. To achieve this objective the analysis of secondary sources (scientific articles and reports) focusing on the history and culture of the Oromo people was undertaken. The data obtained from published and unpublished materials were carefully checked and cross-checked and thematically analyzed using qualitative description.

\section{RESULTS AND DISCUSSION}

\subsection{The Genesis and Development of Oromo Studies}

Ethiopian Studies as a discipline was founded in Europe in the $17^{\text {th }}$ century. Of the three well-known foreign scholars, who made greater contribution for the genesis of Ethiopian Studies and the one who may be called the 'father of Ethiopian Studies' in Europe is Job Ludolf (1624 - 1704). Other important scholar is James Bruce, whose achievement is well- known in the field of travel and exploration. The third equally important foreign scholar is August Dillmann (1823 - 1894), who is known to have baptized the re-founder of Abyssinian Studies, the Ludolf of the $19^{\text {th }}$ century (Messay, 1996: 1-2).

Since its genesis, Ethiopian Studies treated largely different issues related to the various aspects of the peoples of Northern Ethiopia. But gradually in continued considering the various aspects of peoples Southern Ethiopia, one of which is the Oromo people. Besides, issues related to the Oromo are also studied abroad by expatriate Ethiopians. However, issues related to Oromo peoples were considered by foreign scholars starting from the $1^{\text {st }}$ half of the $19^{\text {th }}$ century. The genesis and development of the study of the different aspects of the Oromo can be seen by dividing into three main phases. The first phase is from its beginning in late 1830s up to 1950s, i.e., until the eve of the opening of the Haile Selassie I University. The second phase is from 1960s, i.e., from the opening the Department of History in Haile Selassie I University and the foundation of Institute of Ethiopian studies, up to the early 1980s. The third phase is from the end of the 1980s, the time when the context of Ethiopian historiography was drastically changed, to the present times.

\subsubsection{Oromo Studies from Late 1830s up to 1950s}

Oromo Studies obtained the first impetus in the late 1830s and early 1840s as a result of the accidental arrival of Oromo slaves in Europe and the subsequent drive of protestant missionaries in to Ethiopia (Pankhurst, 1976: 205). The early $19^{\text {th }}$ century was characterized by slave trade in many parts of Ethiopia. A significant number of slaves came from the Oromo speaking areas of the country and were taken to Arabia and Europe. The first of these Oromo slaves, who reached Paris in 1830s, were the youth men Ware and Gaboan, who were taken from the region of Limu. The arrival of these Oromo young men in Paris was significant from the perspective of Oromo Studies in that they provided the famous French geographer Edme Francois Jomard with a considerable body of geographical, linguistic and other materials which enabled him to publish the text, in Roman script and French translation, which are the first recorded pieces of Oromo oral literature (Ibid: 171-174).

In the same trend, the arrival of other four Oromo slaves in Germany also destined to assist the cause of scholarship in Oromo Studies. These Oromo young men were Akafede Dalle, Otshu Aga, Ajiame and Aman Goda, taken from Borana, Limu, Guma and Goma regions, respectively. In the meantime, these Oromo slaves were intercepted by young German named Karl Tutschek, who had an interest to conduct scientific study in Africa. Based on the information obtained from these four Oromo informants, Tuschek made good progress that towards 1840 he presented the first sketch of Oromo grammar and exhibited a tentative Oromo dictionary (Ibid, 174-184).

Encouraged by the effort of Karl Tutschek, several foreign travelers, who came to Ethiopia, independently developed an interest in Oromo language. For instance, the French envoy Rocket Hericourt, who arrived Shewa at the beginning of October 1839, was quick to appreciate the distinctive character of Oromo culture and in 1841 he published a book which tells how the Oromo had their religious ceremonies under large trees, described the dance of the Oromo women and enumerated the Oromo clan of Shewa. Besides, a French scientific mission dispatched to Ethiopia by King Louis Philippe in 1839 also gathered a certain amount of Oromo linguistic materials and 
published a 16 page "vocabulaire Galla" in 1849 (Ibid: 185). Other early European scholars such as C. Beke, L. Krapf, Antoine, D. Abbadie and W. C. Plowden also made great contribution to the development of Oromo Studies (Messay, 1996: 98). Thus, as the result of the contribution of Oromo slave informants and scientific missionaries, Oromo Studies made spectacular progress within a very short period of time. The Oromo language till then unknown a broad was recorded between 1840 and 1845 in no less than one dictionary, their vocabularies, a grammar, and translation of two of the Gospels was also made. Within a few years, increased contact between Ethiopia and outside world lead to a new era in Oromo Studies (Pankhrust, 1976: 206).

\subsubsection{Oromo Studies from 1960s to the Early 1980s}

The foundation for the development of professional historiography was laid in Ethiopia in the early 1960s with the opening of the Department of History in the then Haile Sellasie I University and the emergence of Institute of Ethiopian Studies (Crummey, 1990: 103). In the period from 1960s until the early 1980s, the Oromo Studies were run by a few Ethiopianist and Ethiopian scholars. The list of Ethiopianist (foreign) scholars include, among others, B.W. Anderzejewsk, Morchachi Abir, Baissua Lemmu, Harbert S. Lewis, W. C. Plowden and James Mc Cann. For instance, Anderzejewisk's $(1960,1964,1970$ and 1976) scholarly works dealt with issues focusing on Oromo dialect and the position of the Oromo in the Cushitic group. Abir's (1865) work dealt with the emergence and consolidation of the monarchies of Enarea and Jimma in the first half of the $19^{\text {th }}$ century. Baissua's (1971) work dealt with the democratic political system of the Oromo of Ethiopia. Lewis's (1965 and 1966) works dealt with the Oromo monarchy of Jimma Aba Jifar and the origin of Oromo and Somalia, respectively. Plowden's (1968) work dealt with travels in Abyssinia and the Oromo country with an account of a mission to Ras Alula and Mc Cann's (1978) work also dealt with perspectives on Neftegna Gabbar System (Asefa, 1966: 117-123).

The Ethiopian Revolution of 1974 brought radical changes to the political and economic scene of Ethiopia. It closed long chapter in the country's political history and opened a new and highly disputed episode in the country's historiography. With the declaration of socialism as the new ideology of the state, scholars felt safe to employ analytical concepts such as class struggle and the primacy of economics in their analyses and in selecting research topics. Social scientific inquiry also focused on the study of the subjugated and neglected peoples of Ethiopia. Many scholars turned to the production of knowledge about the activities and experiences of previously ignored classes, ethnic groups, and marginalized segments of Ethiopian society. These changes coincided with the intellectual ferment in academia that legitimized the use of oral information in the reconstruction of history and emphasized the critical role of the less dramatic historical forces, such as agrarian change, rural political economy, property relations and social institutions. Ethiopian studies underwent a significant transformation as scholars focused less on the powerful and the dominant, and gave more attention to the non-Semitic peoples of southern Ethiopia. Perhaps because of their numerical significance as the largest ethnicity, the Oromo figured prominently among the ethnic groups that became the focus of the new scholarship in the period under consideration. A number of studies were undertaken in the Oromo society exploring class relations, state formation, protest movements, land alienation and agricultural production (Ezekiel, 2002: 2-3).

In the period under consideration, apart from expatriate scholars already mentioned, Ethiopian scholars attending their studies a broad and in Addis Ababa University, also contributed for the development of Oromo Studies, by undertaking their M.A. and Ph.D dissertation on different aspects of the Oromo people. These well-known Ethiopian scholars include Mered Wolde Aregay, Muhammed Hassen, Negaso Gidada, Tesema Ta'a, Guluma Gemeda, Tekalign Wolde and Danile Ayana, to mention but a few. For instance, Merid's (1971) School of Oriental and African Studies (S.O.A.S) Ph.D. dissertation dealt with Southern Ethiopia and the Christian Kingdom with special reference to the Oromo migrations and their consequences. Muhammed's (1983) S.O.A.S Ph.D dissertation re-evaluated the available materials for Oromo early history with an emphasis on southwestern region. Negaso's (1984) Frankfort University dissertation deals with the Sayo of western Wallaga. Tesema's (1980) Addis Ababa University (A.A.U.) M.A. Thesis and 1986 Michigan University Ph.D dissertation dealt, respectively, with a historical survey of the Oromo of Wollega and the political economy of Western and Central Ethiopia. Guluma's (1984) A.A.U. M.A. Thesis dealt with the process of state formation among the Oromo in the Gibe region. Tekalign's (1984) A.A.U. 
M.A. Thesis and 1986 University of Illinois Ph.D dissertation dealt, respectively, with slavery and the slave trade in the kingdom of Jimma and the condition of serfs, slaves and shifta, and the mode of production in Southern Ethiopia. Daniel Ayana's (1984) A.A.U. M.A. Thesis dealt with protestant missions in Wollega (Crummay, 1990: 115).

Thus, the Ethiopianists and Ethiopian works together transformed Oromo Studies into a new phase and came to represent an important landmark in Oromo Studies. Basing their works largely on oral traditions, the authors of the studies brought legitimacy to Oromo oral traditions as historical sources. The fact that most of the scholars involved were Oromo also signaled that Oromo intellectuals have come of age to produce Oromo-centered scholarship from insider's perspective (Ezekiel, 2002: 2-3).

Although a few Ethiopian scholars contributed for the development of studies on different aspects of the Oromo people in the period under consideration, different sources indicate that conditions were not favorable in Institute of Ethiopian Studies, founded in 1963, for the study of different aspects of the Oromo people, such as Oromo history and culture (Asefa, 1996: 106). Particularly in the 1970s, the history of the Oromo was said to have overlooked in the Ethiopian Studies. With regard to this issue, Muhammed Hassen (1990: Xi) asserts that "careful examination of the sources on Ethiopia reveal that Oromo history has been totally neglected ... for instance, an important task of Taddesse Tamrate ... published in 1972 ... said [nothing] about the Oromo." Asmerom (2000: xiv) also declared his eyewitness account about the then condition of Ethiopian Studies stating "I have watched the evolution of ... Ethiopian Studies ..., initially as an active participant and later as an estranged observer. It was a very inhospitable forum for those of us who wish to re-assess the Oromo Cushitic role in the national culture and history." Such conditions were said to have forced Oromo scholars to go out of the country and to establish a study institution of their own known as Oromo Studies Association.

Oromo Studies Association is a scholarly, multidisciplinary, non-profit organization registered in the United States of America. It was established by international scholars, covering all continents, who were concerned with lack of adequate knowledge about the Oromo people (OSA, 2010; OSA, 2018). Since this association was established by Oromo scholars, its members engaged themselves largely in the study of the socio-cultural, economic and political conditions of the Oromo and published their research findings in their journal called Journal of Oromo Studies. This journal is issued twice a year. The journal publishes articles pertaining to all areas of Oromo Studies past, present and future, including topics related to the Oromo Diaspora worldwide. Its interdisciplinary scope and revisionary approach offers readers a critical view of the socio-economic, political and cultural achievements of the Oromo people in their interactions with the people of the Horn of Africa (OSA, 2010). It is one of the first and longest running publications dedicated to the treatment, discussions and analysis of the various aspects of the Oromo people (OSA, 2018).

\subsubsection{Oromo Studies from the End of 1980s to the Present Times}

By the end of the 1980s, the context of Ethiopian historiography drastically changed and historiography works began to privilege class and class relations, the economy and its impact on society. Attention has broadened to include ethnic groups, most prominently the Oromo. After this period, historical and cultural studies that explain large scale and long term social changes in the Oromo society began to take place both inside and outside the country (Crummy, 1990: 105). Some scholars committed themselves to serious scholarship and their works are now becoming a stepping stone in writing the social and cultural history of the Oromo people. These scholars include Enrico Cerulli, Von Eike Haberland, Parl Baxter, B.S. Andrzejewski, Herbert Lewis, Asmerom Legesse, Lembert Bartels, Atessando Triulzi, Gunnar Hasselbalatt, Hector Blackhurt, Karl Eric Knutsson, Ulrich Braukamper, Modechai Abir, Gudrun Dahl, John Hinnant, Jan Hultin, Bonnie K. Holcomb, Aneesa Kassam, Hilarie Kelly, Jonathan Owens, Domenico Pecci, Gunther Schlee, Paolo Tablino, W.I. Torry and M.W. Moreno. These scholars have studied, among others, about the Oromo political economy, culture, language, social structure, religion and nationalism (Asefa, 1996: 116).

When the Derg was overthrown in 1991, the new rulers transformed the whole administrative conditions of the country. Governance and the administration of justice came to rest on linguistic and ethnic affiliation as the nations and nationalities of the country were permitted to cultivate their languages and ethnic identities. All of these measures created a suitable condition for writing Ethiopian history in a new perspective (Ezekiel, 2002: 4). Currently, Oromo Studies is undergoing a promising advancement both inside and outside the country. Inside the country, Ethiopian 
historiography in particular and Ethiopian Studies in general, broadened their magnitude of inquiry of previously forgotten and overlooked areas, themes and ethnic groups, the most important of which is the case of the Oromo (Bahru, 2000: 17-18). Outside the country, Oromo Studies Association is also playing significant role to the study and documentation of Oromo history and culture. The regular publication of Journal of Oromo Studies has been a good instrument in the production and dissemination of knowledge about the Oromo (OSA, 2018; OSA, 2010).

\subsection{Major Areas of Disagreement among Scholars on the History and Culture of the Oromo People}

Both Ethiopian and Ethiopianist scholars forwarded some contradictory views over the history and culture of the Oromo. Of these areas of disagreement, the major ones, which this paper tries to address, are the issue of the original homeland of the Oromo, early relation of the Oromo with the Christian highland kingdom, the issue of the existence of 'clear-cut' boundary between Abyssinia and the Oromo land, mode of the livelihood of the Oromo before and during the $16^{\text {th }}$ century, the possession of material culture and contribution of the Oromo for Ethiopian civilization, and the nature of Menelik's expansion into Southern Ethiopia.

There are contradictory views among scholars with regard to the original homeland of the Oromo. Some writers say that the Oromo are new comers to the Ethiopian region or the Horn of Africa, and others say that the Oromo are indigenous to the Horn of Africa. Among the well-known advocates of the former view are, among others, writers like Taye G/Mariam and John Buchhlzer. Taye (cited in Assefa, 1996: 99) says that "the Oromo came to Ethiopia from Asia." While saying this, Taye didn't present tangible evidence for his hypothesis. Supporting the idea forwarded by Taye, John Buchholzer (1956: 129) also claims that "The Oromo migrated from Asia to Africa and then were pushed by their enemies from Tanganyika through Kenya to the Horn of Africa." Obviously, these two writers regard the Oromo as outsiders and newcomers not only to the Ethiopian region but also to whole of the continent. The advocates of the view that the Oromo are indigenous to the Horn of Africa include, among others, Harberts S. Lewis, Darrel Bates, Muhammed Hassen, Bonnie K. Holcomb, Sisai Ibssa, Edward Ullendrof and M.D. Almeda. For instance, Holcomb and Sisai (1990: 5) assert that "the Oromo homeland was well watered central zone highlands and lowlands that stretched across the centre and south of the Horn of Africa." By the same token, Ullendorf (1960: 41) also claims that "[the Oromo's] original habitat was probably the corner of the Horn of Africa, but continued Somali pressure drove them west and southeast." Muhammed Hassen (1990: xiii) also claims that "[the Oromo] had lived in the highlands of Southern Ethiopia for the greater part of their history. They are one of the indigenous peoples of Ethiopia. To consider them as new comers is a claim which has no historical foundation what so ever." Although the specific location of the origin of the Oromo varies, the latter group of scholars concluded that the Oromo are one of the indigenous peoples of the Ethiopian region or the Horn of Africa.

With regard to the early relation of the Oromo with the Christian highland kingdom, a few scholars claim that the Oromo arrived the territory of the Christian highland kingdom before the fourteenth century and others assert that the Oromo arrived the Christian highland kingdom only in the $16^{\text {th }}$ century. The well known advocate of the former view is Muhammed Hassen (1990: xii), who claims that "some settled sedentary agricultural Oromo groups lived in and to the south of what is today the region of Shoa before the $14^{\text {th }}$ century. ... [Therefore], the historical wisdom that the Oromo arrived in the Christian kingdom only in the sixteenth century is incorrect." The second view that the Oromo arrived the Christian Highland kingdom only in the $16^{\text {th }}$ century is advocated by scholars such as Harbert S. Lewis and Edward Ullendrof. For instance, H. S. Lewis (1966: 27) asserts that before 1530, the Oromo confined themselves only in Southern Ethiopia and Northern Kenya, but in the middle of the $16^{\text {th }}$ century, the Oromo began their expansion into the north. By the same token, Ullendroff (1960: 41) also claims that "it was only in the $15^{\text {th }}$ and $16^{\text {th }}$ century that [the Oromo] began to penetrate into the Abyssinian highlands."

The question of the existence of a 'clear-cut' boundary between Abyssinia and the Oromo land is also the other point of disagreement among scholars. With regard to this point, some scholars assert that Abyssinian and the Oromo had a 'clear-cut' boundary prior to the late 1800s and others claim that a 'clear-cut' boundary between states not only in the Horn of Africa, but also in other areas of the continent, came into existence only at the end of 1800 s and the advocates of this view continue saying that even after the late $19^{\text {th }}$ century, there is no 'clear-cut' boundary with demarcation which put 
Abyssinian and the Oromo land as a separate entities. The main architects of the former view are Holcomb and Sisai (1990: 4-5) who claim that "[f]or at least five centuries of recorded history prior to the scramble for Africa in the late 1800s, the Abyssinian and the Oromo had tested each other and maintained consistent and clear-cut boundary between their homelands."

The second view that Abyssinia and the Oromo had no 'clear cut' boundary both before and after the late 1800s is advocated by scholars such as Bahru Zewde and Addis Hiwot. Bahru (1998:143) asserts that Ethiopia attained a 'clear cut' boundary, with the neighboring countries, only in the last quarter of the $19^{\text {th }}$ century and in the early $20^{\text {th }}$ century by territorial demarcation and delimitation agreement made between Emperor Menelik II and the neighboring colonial powers, such as Italy, France and Britain. With regard to the formation of modern Ethiopia, Addis Hiwot (1975: i) also claims that "[t]he same historical force that created the Gold Coast, the Ivory Coast, the Sudan and Kenya [in the late $19^{\text {th }}$ century], were the very ones that created modern Ethiopia." So, both Bahru Zewde and Addis Hiwot claim that modern Ethiopia came out with a "clear-cut" and defined territory only after the last quarter of the $19^{\text {th }}$ century including the land of the Oromo as part and parcel of its territory and the work of these two scholars, indicate that Abyssinia and the Oromo had no "clear-cut" boundary throughout history.

With regard to the mode of the livelihood of the Oromo before and during the sixteenth century, some scholars claim that the Oromo were nomadic herdsmen before and during their migration and other scholars treat that the Oromo were mixed agriculturalists. One of the advocates of the first view is Edward Ullendrof. In his explanation of the mode of the livelihood of the Oromo, Ullendrof (1960: 41) claims that the Oromo were nomadic herdsmen before their migration into the regions of the Christian highland kingdom in the $16^{\text {th }}$ century. The second view that the Oromo were mixed agriculturalists before their migration in the $16^{\text {th }}$ century was advocated by scholars like Muhammed Hassen (1990: xiii) who asserts that "[o]riginally, the Oromo were not nomads. They were engaged in mixed farming. Some of them began to become pure pastoralists only after they moved from the highlands to the lowland areas." Similarly, Holcomb and Sisai (1990: 5) also claim that "[t]he Oromo ... were organized under participatory form of government that incorporated persons of agricultural, pastoral and mixed forms of livelihood into public life." By the same token, Asefa (1993: 18) also asserts that "[t]he Oromo were mixed agriculturalists (farmers and herders) before they began their sixteenth century expansion. They primarily reared cattle and sheep and grew barely and used this production for economic ritualistic purposes. After they expanded and settled, most of the Oromo continued their practice of cultivating barely and other crops on the highlands and herding cattle on the lowlands and pursued both activities." Tesema Ta'a also argues that, since their settlement in Western Ethiopia, through their qotissa system the Maccaa Oromo have used their own indigenous agricultural knowledge and practices to obtain surplus harvests and maintain balanced relationships between crop cultivation, livestock raising, plant life, and environmental conservation. It is this indigenous qotissa system which enabled the Maccaa Oromo to cope with periodic disruptions caused by climatic variations and political upheavals (Ezekiel, 2002: 4).

With regard to the possession of material culture and contribution for Ethiopian civilization, some scholars say that the Oromo had no material culture and they didn't contribute anything for Ethiopian civilization and others say that they had their own distinct cultural elements and they also contribute their own part for Ethiopian civilization. One of the main advocates of the first view is Edward Ullendrof (1960: 76), who asserts that "[the Oromo] has nothing to contribute to the civilization of Ethiopia, they possess no material or intellectual culture, and their social organization was at a far lower stage of development than that of the population among whom they settled." The second view that the Oromo had their own distinct culture and civilization is supported by scholars such as Muhammed Hassen, Assefa Jaleta, Asmerom Legesse, Bonnie K. Holcomb and Sisa Ibisa, only to mention a few. For instance, Muhammed Hassen (1983: 3) claims that "the various Oromo tribes ... shared a common language, a culture, an oral literature, customs and manner, law, a 'government,' and institutions such as the office of Ababa Gada, Qallu and the Bokku," and he also continues saying that "A Qallu was a high priest who was the spiritual leader of Oromo traditional religion" (pp.6-7). Asefa (1983: 26) also claims that "the gada, as a political, economic, social and religious institution, was the pillar of Oromo culture and civilization. ... The gada system consolidates this people both militarily and organizationally in expanding their territory for their increased population and cattle." 
There are two different views among scholars with regard to the nature of Menelik's conquest of Southern Ethiopia in the last quarter of the $19^{\text {th }}$ century. The first view explains Menelik's conquest of Southern Ethiopia as 'colonial occupation' and the second view explains Menelik's conquest of Southern Ethiopia as territorial expansion. The main advocates of the first view include Bonnie K. Holcomb, Sisai Ibsa and Asefa Jaleta. Speaking about the colonialist image of Ethiopia (Menelik), Holcomb and Sisai (1990: 1) assert that "Ethiopia is ... a geographical unit created when Abyssinia $\ldots$ expanded in the mid 1800 s by conquering independent nations in the region using firearms provided by European power." By strengthening the view of Holcomb and Sisai, Asefa (1996: 100) also claims that "Oromo was ... colonized [by Abyssinia] during the last decades of the $19^{\text {th }}$ century." The second view which explains Menelik's conquest of Southern Ethiopia, in the last quarter of the $19^{\text {th }}$ century, as territorial expansion was supported by scholars such as Teshale Tibebu, Messay Kebede and Bahru Zewde, only to mention a few. For instance, in his deconstruction of colonialist image of Ethiopia, Teshale (1996: 421) asserts that '[t]he so-called 'black colonialism' ... ascribed to Ethiopia is based on an amazing ignorance of ... state formation in the $19^{\text {th }}$ century Africa. Africans throughout the continent were forming states through territorial expansion and political centralization ... Menelik's expansion was the largest African scene." By the same token, Bahru (1988: 152) claims that "[Menelik's] territorial expansion was in a sense a continuation of the process started by the Shewan rulers of the $18^{\text {th }}$ and early $19^{\text {th }}$ century."

The above mentioned points of disagreement underscore that much of what has been written by many Ethiopian and Ethiopianist scholars on the history and culture of the Oromo seems to be an opinion or idea that is not based on definite knowledge. For instance, the written records of the $16^{\text {th }}$ century, on different aspects of the Oromo people, are full of cultural, religious and ethnic biases, which are not accepted by insiders to Oromo culture and history. These early writings have greatly influenced several writers of the late period (Tesema, 1994: 988). Here, the most important question to be raised is why scholars come out with different interpretations with regard to the socio-cultural and economic history of the Oromo people? One of the factors that contributed for such kind of disagreement of scholarly works, over the study of the Oromo, is lack of effective use of various oral traditions, linguistic evidences and social practices of the Oromo (Muhammed, 1990: xi-xii). Besides, religious, ethnic and political biases also contributed for the emergence of such contradictory scholarly works on different aspects of the Oromo.

\section{CONClusion}

This paper is a preliminary overview of tends of Oromo Studies from the late 1830s to the present times. It tried to show how the study of the different aspects of the Oromo people began and how it developed from time to time, and major areas of disagreement among scholars on different aspects of the Oromo. The Oromo language has a well developed oral literature which has been transmitted by words of mouth and preserved in the memories of the people. This oral literature is rich in folk tales, stories, songs, vocabularies, proverbs and poems. They are passed from one generation to another through elders. The Oromo parents also teach their children songs, proverbs, games and riddles to encourage these skills. Oromo elders usually quote lines of poetry in their speeches spontaneously to suit with an important occasion. Most Oromo adults know a number of songs, poems and riddles. However, in spite of greater role of oral tradition in the Oromo society, there are no meaningful numbers of books written on various aspects of the Oromo in Oromiffa language (Feyisa, 1996:18), especially before the last decade of the $20^{\text {th }}$ century. This is emanated from the fact that Oromiffa was not used as written language in Ethiopia, which hindered the use of the language for educational instruction, religious practices, governmental activities, documenting the cultural, social, economic and political activities and achievements of the Oromo people. As a matter of fact, most of the early and some contemporary works on the Oromo people suffered inaccuracies and biases, especially those works done by outsiders (non-Oromo). So, any future scholarly work on the Oromo as well as on other peoples of Ethiopia will continue to suffer from inaccuracies, incompleteness, biases and distortions of the past unless oral traditions, linguistic evidences and social practices of peoples under consideration are carefully, systematically and methodologically employed. Lastly, I would like to close my paper by reflecting a short excerpt forwarded by Messay Kebede (1996):

\section{A society cannot properly map out and accomplish}

$$
\text { its feature if it mistakes its history ... (p.1) }
$$




\section{REFERENCES}

Addis Hiwot. (1975). Ethiopia: From Autocracy to Revolution. London: Merlin Press

Asmerom Legesse. (2000). Oromo Democracy: An Indigenous African Political System. Trenton: The Red Sea Press.

Asefa Jaleta. (1993). Oromia and Ethiopia: State Formation and Ethno, National Conflict, 1868- 1992. Boulder: Lynne Rienner Publisher. (1996). "The Struggle for Knowledge. The Case of Emergent Oromo Studies." In African Studies Review, Volume, 39, N.2, pp. 96-123

Bahru Zewdie.(1998). A Short History of Ethiopia and the Horn. Addis Abeba: Addis Ababa University Press. (2000). “A Century of Ethiopian Historiography” In Journal of Ethiopian Studies Vol. xxxiiI, N.2, Nov., pp. $1-26$

Buchholzer, J. (1956). The land of Burnt faces. New York: Robert M. Mc. Bridge

Braukamper, U. (1982-83). “Ethnic Identity and Social Change among Oromo Refugees. 'In The Horn of Africa, Northeast African Studies, Vol. 4, No. 3, pp. 1-15

Crummey, D. (1990). "Society, State and Nationality in Recent Hagiography of Ethiopia." In Journal of African History 31, No.1, pp. 103-119

Ezekiel Gebissa.(2002). "Introduction: Rendering Audible the Voices of the Powerless." Northeast African Studies, New Series, Vol. 9, No. 3, Special Issue: The Oromo in Ethiopian Studies: Confronting Challenges to Politically Engaged Scholarship (2002), pp. 1-14

Ezekiel Gebissa.(2018). “Indigenous Universal Principles: Oromo Perspective on Human Rights." The Journal of Oromo Studies. Volume 25, Number 1 \& 2, pp 1-24.

Ezekiel Gebissa. (2017). The Oromo Studies Association (OSA): An Autonomous Scholarly Organization in the Service of the Oromo People (https://www.zehabesha.com/the-oromo-studies-association-osa-anautonomous-scholarly-organization-in-the-service-of-the-oromo-people/

Feyisa Demie. (1996). "Historical Challenges in the Development of Oromo Language and Some Agenda for Future Research." The Journal of Oromo Studies. Volume 3, Number 1 \& 2, pp.18-27

Holcomb, B. and Sisai Ibssa. (1990). The Invention of Ethiopia: The Making of Dependent Colonial State of a North East Africa (Trenton: The Red Sea Press).

Hultin, J. (1975). "Social Structure, Ideology and Expansion: the Case of the Oromo of Ethiopia," Ethnos , 18, 1-4, pp. 273-84.

Lewis, S. H. (1966). “The Origin of the Galla and Somali.” In Journal of African History, Vol. 7, pp 27-46

Messay Kebede. (1996). “Eurocenterism and Ethiopian Historiography: Deconstructing Semitization.” In International Journal of Ethiopian studies, Vol. 1, No. 1 (Summer/Fall 2003), pp. 1-19

Oromo Studies Association (OSA). (2010). The Journal of Oromo Studies. Volume 17, Number 2

Oromo Studies Association (OSA). (2018). The Journal of Oromo Studies. Volume 25, Number $1 \& 2$

Pankhrust, Richard. (1976). “Beginning of Oromo Studies in Europe.” In Journal of Black Studies, V. 26 N. 4., pp. 171-206.

Pausenwang, S. (2009). “The Oromo between Past and Future: Introduction.” In Pausenwang (Ed.), Exploring New Political Alternatives for the Oromo in Ethiopia: Report from Oromo Workshop and Its after-effect. R2009:6 CMI CHR. MICHELSEN INSTITUTE, PP.1- 13

Ullendrof, E. (1960). The Ethiopians: An Introduction to Country and People. London.

Citation: Alemu Alene Kebede \& Yirsaw Tadele Alem. “A Preliminary Overview of Trends of Oromo Studies in and Outside Ethiopia” International Journal of History and Cultural Studies (IJHCS). vol 6, no. 4, 2020, pp. 57-65. doi: DOI: https://doi.org/ 10.20431/2454-7654.0604005.

Copyright: (C) 2020 Authors. This is an open-access article distributed under the terms of the Creative Commons Attribution License, which permits unrestricted use, distribution, and reproduction in any medium, provided the original author and source are credited. 